\title{
Causal Claims and the Study of Ethnic Conflict
}

\author{
Marie-Eve Desrosiers and Srdjan Vucetic \\ University of Ottawa \\ 10,000 words
}

\begin{abstract}
What does causation mean in conflict studies? Using a sample of published qualitative, article-length studies on the Rwandan and Yugoslav wars, we find a lack of reflexivity over causal claims in scholarship on conflict. Causal language is not as pervasive as expected, asserted cause-effect relationships are rarely fully explicated, and scholars under-explore their causal assumptions. Considering that ideas on causation necessarily condition explanations of conflict, including "ethnic" conflict, this is a major research issue. While there exists a lively debate between different causal narratives regarding the onset of conflict-with studies alternatively stressing "attitudes," "conditions," or both-it stops short of addressing issues at the deeper level of causal understandings. For the most part, studies subscribe to the search for empirical generalization, thus limiting attendant debates to a single model of causation. These findings indicate that conflict studies literature would benefit from greater reflexivity and pluralism with regards to causation, and paying more attention to philosophical debates on the subject. We provide a basic outline of this reflexive agenda.
\end{abstract}

Keywords ethnic conflict, causation, conflict studies, Rwanda, Yugoslavia, reflexivity

\section{Introduction $^{1}$}

Scholars of conflict variously interpret the Mano River War, a commonly used label for a 15-

year period of large-scale violence in four West African countries, as ethnic in terms of

primary causes, its effects, or not ethnic at all (Hoffman 2011; Vigh 2006). In contemporary

conflict studies, including scholarship on what are commonly called ethnic conflicts, such

variance is common. Indeed, this literature is replete with both case-specific or general

accounts of what lies behind collective violence, which factors matter, and how. A discussion

\footnotetext{
${ }^{1}$ We humbly dedicate this paper to our dear colleague and friend, Lee Ann Fujii, whose scholarship greatly inspired us both. She will be sorely missed. We thank Mallory Bikinas and Caroline Roy for research assistantship and Kevin McMillan for critical comments. A supplementary file summarizing the sample, coding, inter-coder reliability test, additional data analysis and interpretation is available upon request.
} 
is missing, however, on what constitutes a cause or on how scholars' assumptions regarding causation relate to their arguments and shape the production of knowledge about conflicts. This is a major research issue. As Lebow puts it, causation is the "900-pound gorilla in the room, to whom everyone defers but no one mentions" (2014, ix).

Do scholars of ethnic conflict talk about and understand causation the same way across their studies? If they do, or do not, what are the implications? These are questions with some of the highest stakes: the causal language we use and causal assumptions we hold shape how we frame the conflicts we study, including the decision to categorize them as "ethnic". Our causal assumptions further shape our ability to engage constructively with other scholars studying the same phenomenon, and ultimately how we respond to conflict in our policy, politics, and ethics. Not asking these questions continues to feed our 900-pound gorilla, and hobbles knowledge production.

To examine the nature and range of claims scholars make about ethnic conflict, we build on frameworks for causal meta-analysis recently introduced by "reflexivists" in nearby fields (e.g. Jackson 2011; Lebow 2014; Vaidyanathan et al. 2015). We begin by proposing an original distinction with regards to causal claims between what we coin "causal narratives" and "causal understandings". We define the first as statements or arguments that involve implicit and explicit hypotheses, justifications, and explanations regarding causal relations behind a phenomenon. We define the second as the implicit or explicit philosophical priors or assumptions regarding causation, and which causal view is the most appropriate for constructing causal narratives and capturing how causation operates in the social and political universe. Using this framework, we code a sample of forty three qualitative, case study-based articles on large-scale violence in Rwanda and Yugoslavia in the 1990s published in English language journals over the last quarter century. 
We find that explicit causal language is not the rule, nor is the explicit conceptualization of causal explanations. The majority of studies addresses causal antecedents through the narratives of "attitudes" versus "conditions," one of the reigning and liveliest debates in conflict literature. However, these studies do so without reflecting on the concepts of cause and effect, or on the causal assumptions they bring to bear on their work. The same goes for the concept ethnicity itself: while multiple studies vigorously reject the view of either the Rwandan or Yugoslav wars as primarily ethnic, only one study in the sample explicitly argued against imposing ethnicity as a category. At the deeper level of causal understandings, the bulk of studies work with a Humean stance on causation, in particular what Jackson (2011) in his analysis of International Relations (IR) scholarship calls "empirical generalization." Even authors striving to depart from this particular understanding tend to use rhetoric associated with it. The few studies that employ counterfactuals, a causal analysis tool, use them superficially, while those invoking causal mechanisms rarely define the concept.

Together, these findings indicate that current causal thinking is excessively narrow. While conflict studies defines itself as pluralistic and inter-disciplinary, the majority of the sampled studies implicitly subscribe to a single philosophy of causation. Debates that center on which causal factors lead to collective violence matter more than definitions or conceptualizations of causation. Relatedly, and in contrast to contemporary sociology and anthropology where efforts are made to keep categories of analysis and categories of practice separate, this literature tends to conflate them, in turn reproducing problematic, depoliticizing ontologies (Malešević 2006, 4; also see Wimmer 2013, Ch. 2).

These findings confirm the need for greater reflexivity - that is, to borrow from Finlay (2002, 209), for greater self-awareness about the language, notions, and assumptions we as scholars bring to bear on our research process, and how we approach the realities we aim to explain. Reflexivity is a shared responsibility, meaning that both the predominant empirical 
generalizers and their critics stand to benefit from engaging with causation in this manner. A renewed dialogue on "what made this happen?" in the study of ethnic conflict and a related conversation on how ethnicity fits in the debate is in the best interest of the subfield of ethnic conflict studies, rather than the continued domination of unreflexive, empirical generalizationstyled causal claims and disclaimers, wholesale shifts to alternative approaches, or the stovepiped evolution of both camps. Our goal is not to promote one approach over others- this would be antithetical to our call for more reflexivity and pluralism. Rather, it is to provide a better sense of causation in conflict studies, how it is conveyed, understood, and made to matter, as only meta-analyses can. Accordingly, we mobilize select insights from the work we sampled to outline the potential value added—and value subtracted—of varying one's analytical (causal narrative-level), but mostly meta-analytical (causal understanding-level) lenses. $^{2}$

In the section that follows, we develop our framework for mapping out causal claims. Next, we outline our sampling strategy and discuss our findings. We then turn to a discussion of what a more reflexive and indeed pluralistic position on causation would do to and for the study of ethnic conflict. Our contribution is thus twofold. First, we demonstrate that causal claims in the study of ethnic conflict operate on two epistemic levels-superficially as causal narratives, and philosophically as causal understandings. Second, we outline a research agenda for a more reflexive study of ethnic conflict, which thus far has not lent itself to meta-

\footnotetext{
${ }^{2}$ We build on different causal assumptions and traditions in our own work. Desrosiers primarily adopts an empirical generalization stance, though a conditioning variant, while Vucetic is more pragmatic in his approach to causal understandings. We are aware that there is a debate in reflexivity studies over the extent to which scholars can meta-analyze their own subject positions, as scholars in general (Hamati-Ataya 2013) and as "ethnic" conflict researchers in particular (Gunaratnam 2003).
} 
analysis, contrary to parallel fields such as IR (e.g. Humphreys 2018; Jackson 2011; Lebow 2014).

\section{Ethnic Conflict and Causal Claims}

The very notion of "ethnic conflict" is subject to considerable ontological, epistemological, and normative debates: What is it? How do we know it exists? Should we even use "ethnicity" to make sense of the conflicts we study? ${ }^{3}$ Even against such fundamental and long-standing uncertainties, the literature on the subject is vast, ${ }^{4}$ in part because scholars largely accept a provisional definition of ethnic conflict as armed violence with an identity component, as defined by at least one of the belligerents on ascriptive, historical, or mythical bases. ${ }^{5}$ Ethnic conflicts occur primarily within states, as opposed to between them. ${ }^{6}$

The scholarship on the "why" and "how" of ethnic conflict has grown so much in recent years that it is now possible to speak of it as a subfield of the interdisciplinary field of conflict studies, whether or not we agree with the "ethnic" label. ${ }^{7}$ The first subfield-defining

\footnotetext{
${ }^{3}$ For a survey of some of the key issues, as well as the state of the field of ethnic politics and conflict, see the special issue published in 2017 in Ethnopolitics.

${ }^{4}$ According to Cederman, the term "ethnic" outclassed references to nationalism in political science journals beginning in the 1990s $(2013,533)$. See also Fearon and Laitin $(2000,851)$.

${ }^{5}$ Following the tradition of Horowitz and others, scholars often use the term "ethnic conflict" to encompass conflicts surrounding a broader set of identities, such as religious identities. For example, Horowitz uses the case of Northern Ireland to discuss what he calls "interethnic conciliation in severely divided societies (2002, 193).

${ }^{6}$ We propose this definition as a baseline definition based on relatively common elements used in defining ethnic conflict. We do not necessarily wholly subscribe to this definition, nor was it the basis on which articles in the sample were selected (see below).

${ }^{7}$ Others have gone as far as calling it a field. See Horowitz $(1985,13)$ and Varshney (2009). Note that conflict studies is sometimes subsumed under IR but here we treat it as an interdisciplinary field.
} 
debate, dubbed "greed versus grievances," pinned rationalists against social-psychological and constructivist explanations on the relative importance of rational decision-making and related factors (Fearon 1995; Collier and Hoeffler 2004; Keen 2012), compared to identityrelated processes, including group norms, ethnic symbolism, socialization, hate rhetoric, etc. (Arfi 1998; Kaufman 2001, 2006; Ross 1997, 2007). This divide has recently coalesced around a new debate and the rubrics of "attitudes" and "conditions," whereby the former stresses a focus on sources of mobilization, specifically human drivers, decision-making processes, and attitudes, and the latter focuses on the structural and institutional conditions that shape opportunities for conflict. ${ }^{8}$ Some of these debates have self-consciously foregrounded the issue of causation. The "attitudes" scholars, who predominantly rely on case-based analyses, seek to identify the sources, qua causes, of mobilization and hence of ethnic conflicts. In contrast, "conditions" scholars, whose approaches tend to rely on large-N analyses, are interested in identifying factors they believe correlate to conflict onset. As useful as the distinction between research on sources of mobilization (causes) and conflict onset (correlations) has been for our understanding of "ethnic" conflict, the debate has mostly failed to inspire systematic engagement with notions of causation.

For the reasons mentioned above, this is more than a trivial problem. Indeed, how we understand causation shapes the questions we ask and the answers we get, our ability to engage each other as scholars, as well as the solutions on offer with regards to conflicts. ${ }^{9}$ In response, we propose a reflexive approach to causal analysis in ethnic conflict studies,

\footnotetext{
${ }^{8}$ The division goes back to debates sparked by Fearon and Laitin's study of insurgency, in which they claimed that theoretical attention to "large cultural divisions or broadly held grievances" was largely misplaced (2003, 88). The conditions approach is also known as the "opportunities model" (Steinberg and Saideman 2008, 237).

${ }^{9}$ For previous discussions, see Suganami (1996), Angstrom (2000), Lyall (2015), Greiff and Grieff (2016) and Van Ingen (2016).
} 
building on similar calls for philosophically-grounded causation awareness in IR (Goertz and Levy 2007; Jackson 2011; Kurki and Suganami 2012; Lebow 2014; Guzzini 2017), political science (Schatz 2015), sociology (Abend et al. 2013; Vaidyanathan et al. 2015), and across disciplines (Harré and Moghaddam 2016; McMillan 2018).

We believe that causal analysis not only involves tools for developing explanations, but also a specific view, a blinder, so to speak, regarding social realities, that is shared among members of a scholarly community who build on common, though not always explicit, rhetorical tropes and philosophical assumptions. To start being more reflexive, we can think about explanations based on greed, grievances, attitudes, conditions, and similar constructs as causal narratives - the framing or story-telling used to make sense of causal realities. ${ }^{10}$ Indeed, the choice of words, metaphors, and the hypotheses and notions scholars use to construct substantive causal narratives of ethnic conflict are part and parcel of scholarly knowledge on ethnic conflict. They are an indication of how causal claims are deployed in practice, and often reflect the practices of broader scholarly communities. A scholar would be hard-pressed to make a statement regarding cause and effect that completely falls outside the narrative practices of her scholarly community (Goertz and Levy 2007, 4; Vaidyanathan et al. $2015,3,19)$.

Reflexivity can be further heightened by paying attention to the connection between causal narratives and causal understandings: our background assumptions regarding what

\footnotetext{
10 "Causal narrative" is meant to capture how scholars pull together complex events and factors to shed light on a phenomenon, proposing a fine grained understanding of an event sequence (Lange 2013, 50-1) or help better distinguish among similar event sequences (Mahoney and Rueschemeyer 2003, 366). The concept does not presuppose the content or form the narrative takes. It only foregrounds the process behind talking about causation. For a discussion of explanation and narration with regards to the causes of war, see Suganami (1996, 134-52). For a discussion of narrative theory, see Feldman et al. (2004).
} 
causation is, what shape it takes, how it operates, and what counts as appropriate or meaningful in casual accounts. We do not tell the story of causation from a blank slate, but bring our prior beliefs about causation to the phenomena we study. This is akin to what Lebow calls "deep frames of reference" $(2015,411)$. Whether we acknowledge this or not, causal understandings always enable and/or constrain substantive causal narratives (Goertz and Levy 2007; Lebow 2014, 3). In parallel, causal narratives can also be understood as implementing or articulating scholars' broader causal understandings (Mahoney 2008; Lebow 2014, 3; Vaidyanathan et al. 2015, 4). And because they mirror our deeper causal beliefs, causal narratives serve to further validate and reproduce them.

How we understand causation is often contested, albeit rarely openly. The world of causation, as discussed in philosophically informed debates, is indeed rife with different causal understandings that capture causation in different ways. With an eye to both longstanding and recent debates in IR theory, Jackson (2011) differentiates among four types of causal understandings:

1) Empirical generalization. The core claim behind this type of causal understanding, often associated with positivist accounts, is that "X generally leads to Y" given certain “initial” or "scope" conditions (Jackson 2011, 199; Kurki and Suganami 2012, 403). Empirical generalization is variously associated with the "regularity" and "Humean" view of causation, as well as with the "covering-law," "nomothetic," and "deductive-nomological" models of explanation. ${ }^{11}$ Empirical generalization gives expression to sub-types, namely

\footnotetext{
${ }^{11}$ Some of these associations are more defensible than others. For one, generalization in this sense does not necessarily entail the search for predictions (cf. Jackson 2011, 111; Van Ingen 2016, 390). Similarly, "regularity" should not be conflated with "manipulation," also known as "intervention," which refers to the practice of identifying a causal relation by intervening on the cause to change the effect in a predictable way. "Regularity" and "manipulation" approaches undergird some of the same methods for testing causal claims,
} 
"probability association" claims about events or properties raising the probability of an effect, and claims based on "necessary and sufficient conditions." The so-called "conditioning" approach is another sub-type of the empirical generalization model (Suganami 1996, 127-34; Goertz and Levy 2007; Vaidyanathan et al. 2015, 9-10). It focuses on the environment contributing to the occurrence of an outcome. This stance leads to more complex causal claims, but relies on Humean notions about the constant conjunction of causes and effects and can this be classified as falling within empirical generalization.

2) Dispositional. While there is very diverse literature in both the philosophy of science and in metaphysics on dispositional approaches, Jackson mostly adopts a critical realist view of social reality as layered, where each level of social reality is populated with entities with emergent capacities that influence an outcome. While not all entities are observable, their effects are. Causal analysis aims to trace the combinations of various capacities and how they relate to an outcome (Kurki and Suganami 2012, van Ingen 2016). The social world is subject to individual agents, chance, and nonlinear interactions that render the search for law-like generalization and regularities questionable. In addition, dispositional properties manifest themselves in context-specific ways, such that causal explanations must acknowledge contingency and equifinality. ${ }^{12}$ Critical realists often find value in constitutive

including linear equation modeling, experiments and quasi-experiments, and some comparative case study designs, but they are not the same models of causation (Cartwright 2014, 316-9; Risjord 2014, 219-22).

${ }^{12}$ Equifinality entails interactions across various causal factors and conditions, accepting that there are many paths towards the same outcome (Goertz and Levy 2007, 7). 
analysis $^{13}$ and in deduction based on the logic of INUS (an Insufficient and Non-redundant factor, part of an Unnecessary, but Sufficient condition) causation. ${ }^{14}$

3) Configurational. Here, the emphasis is on "ideal-typical accounts of causal factors, processes, mechanisms, and sequences-which, in their very conceptual one-sidedness, point in the direction of the specific empirical configurations characteristic of particular situations" (Jackson 2011, 199). Configurationalists reject generalizations and the idea of identifying the complex combinations of capacities behind outcomes. They favor causal adequacy, an account of causation based on the practical experience of causes as non-random possibilities. ${ }^{15}$ Counterfactuals are the most important tool for making causal claims: the what-ifs that help identify the conditions under which an "ideal" outcome might have occurred, providing a useful answer as to why and how an actual outcome occurred (Jackson 2011, 115).

4) Dialectical. This view holds that social scientific knowledge itself creates social phenomena-an understanding of constitution rather than causation. This perspective is typically found in studies inspired by various stances associated with "poststructuralist"

\footnotetext{
${ }^{13}$ Constitutive analysis means different things to different scholarly communities. Compare Jackson (2011, 1058) to Ylikoski (2012, 2-4) to McMillan (2018, 145-156).

${ }^{14}$ Mackie's INUS causation refers to a factor that is insufficient (and non-redundant) on its own, but necessary for an outcome $\mathrm{Y}$, and is part of a broader condition that is itself unnecessary but sufficient to bring about the outcome $(1965,246)$. This is different from what Mahoney calls a "combinatorial cause" (or SUIN cause), whereby a causal argument concentrates on the components of a cause that are sufficient but unnecessary, while the causal factor itself is insufficient, but necessary for Y to occur (2008, 419, see also Mahoney et al. 2009, 126-8).

${ }^{15}$ The notion of an adequate cause goes back to von Kries and (early) Weber: a condition whose presence increases the probability of a given outcome by a previously agreed-upon minimum quantity. For Jackson's reinterpretation, see Jackson (2011, Ch. 3.).
} 
scholarship. ${ }^{16}$ These approaches are skeptical of causal claims corresponding to truth, and of causal claims being anything more than a programmatic statement or a status-seeking strategy for those who wish to emphasize the "science" in social sciences.

Naturally, there are inherent limitations when working with typologies (Humphreys 2018). While the one we use here does not necessarily represent a widely held position in the philosophy of causation, it nevertheless helps us think through the heterogeneity of causal understandings, fluidity across causal understandings, and variations among them (Beebee, Hitchcock, and Menzies 2009, Part II). We are also aware of definitional debates surrounding causation and related causal concepts. A case in point is the notion of "causal mechanisms," a term increasingly employed by all sorts of scholars. Sil and Kaztenstein, two "pragmatist" IR theorists, define causal mechanisms as:

all entities-whether individual actions or choices, social relations or networks, environmental or institutional characteristics, specific events or contextual factors, individual cognitive dispositions or collectively shared ideas and worldviewsthat generate immediate effects through processes that may or may not recur across contexts and that may be, but often are not, directly observable $(2010,421)$.

Under this definition, anything from greed and grievances to resource scarcity and state capacity to ethnic mobilization and the ethnicization of discourse are mechanisms. This means that positivists, critical realists, configurationalists, and even poststructuralists could in principle make mechanistic causal claims. From the stricter standpoint of the philosophy of causation, however, mechanistic explanations contradict the regularity view of causation. With these notions and types in mind, at both the causal narrative and understanding level, we now turn to an assessment of work on ethnic conflict over the last decades, though a causal lens.

\footnotetext{
${ }^{16}$ For a review, see Kurki and Suganami (2012).
} 


\section{Sampling and Assessing the Literature}

To capture causation as deployed by scholarship on ethnic conflict, we built our literature sample by concentrating on articles published in peer-reviewed journals, as well as a number of so-called gray outlets that straddle the divide between academic and policy audiences, to reflect the diversity of this work. Our focus on journal articles was principled and pragmatic: articles are likely to be more widely read than books, and a significant portion of books are preceded by the publication of an article(s). Articles therefore represent a wider publication universe while also capturing many of the ideas that eventually appear in books.

The sampling focused on thirty journals considered key outlets for conflict studies in political science, sociology, IR, and security studies, as well as journals dedicated specifically to conflict studies and ethnic conflict. We selected based on prestige and reputation, building on the ISI Thomson Reuters Citation Index and the Teaching, Research and International Policy (TRIP) project, as well as on more "qualitative criteria" (Phillips 2014). This helped to ensure the inclusion of well recognized, but not necessarily ranked or high-ranking journals more likely to publish on war, conflict, and ethnic conflict.

To narrow our sample, we focused our sampling on articles related to violence in Rwanda and the former Yugoslavia in the first half of the 1990s. This consisted of work published between 1991 and 2014 (the start of publication on these conflicts and the last complete year of data collection, respectively). We chose case-based work instead of large-N studies since the latter predominantly propose correlational models instead of causal ones. We focused on Rwanda and the former Yugoslavia because these conflicts are paradigmatic cases in the study of ethnic conflicts, but our sample was assembled independent of the article's author(s)' explicit or implicit definition of the conflict(s), especially with respect to ethnicity.

Paradigmatic cases matter because they exemplify a phenomenon, or have relevant associated 
characteristics and properties (Flyvbjerg 2006, 232-3). They also tend to be popular cases, since schools of thought typically draw on them to demonstrate the value of their arguments. ${ }^{17}$

We selected articles that developed a clear stance on the eruption of violence in one or both of these cases. This yielded forty three articles (sample available in supplementary file online, Appendix 1). Data saturation during coding implied that the sample is sufficient to adequately capture key narratives in the subfield over the last two decades, and to identify key trends with regards to causal understandings.

Table 1: Number of articles by year and case study

\begin{tabular}{llllllll}
\hline Published in & $1991-5$ & $1995-2000$ & $2000-5$ & $2005-10$ & $2010-15$ & Total \\
\hline \multirow{3}{*}{ Rwanda } & 8 & 10 & 8 & 8 & 9 & 43 & $100 \%$ \\
Yugoslavia & 0 & 0 & 3 & 3 & 4 & 10 & $23 \%$ \\
Both & 0 & 1 & 4 & 5 & 5 & 31 & $72 \%$ \\
\hline
\end{tabular}

We interpreted the sample using basic content analysis techniques, borrowing coding practices from established existing literature. We first assessed the presence or absence $(1,0)$ of explicit causal language. In addition, we made a distinction between literal causal language ("security dilemma causes conflict") and metaphorical causal language ("security dilemma triggers conflict," "a catalyst," etc.).

In terms of mapping out specific causal narratives, we coded each article in terms of attitudes- versus conditions-based narratives. We did so for two reasons. First, the attitude versus conditions debate either indexed or subsumed other recent theoretical debates (greed versus grievances, for example). Second, this debate was sufficiently broad to capture a wide

\footnotetext{
${ }^{17}$ A survey of conflict studies literature published over the last decades found that out of fifty eight conflicts, only Rwanda and the former Yugoslavia had enough citations and use across theoretical perspectives to suggest a paradigmatic profile (Desrosiers 2018a).
} 
range of possible causal narratives. ${ }^{18}$ We classified each article in terms of four narrative stances ("attitudes", “conditions", "both/hybrid", or "other" (including "none")), and mapped the specific explanation(s) that each article proposed. We also determined whether ethnicity, or ethnic identity, was identified as a causal factor (either yes/direct or yes/indirect) or not (no).

We also coded the dominant causal understanding suggested in each article, on the basis of language and the context in which it was employed. When appropriate, we classified articles by sub-types within empirical generalization. In addition, we coded articles on the basis of recourse to counterfactuals and to causal mechanisms, coded as present or absent, and, if present, as implicit or explicit.

We assessed all articles and coded them separately. In evaluating the reliability of our coding, we achieved a simple percent agreement of 75 percent or above on all dimensions involving causal narratives and causal understandings (see supplementary file online, Appendix 2). We deem this threshold acceptable considering the complexity of the material.

Table 2 summarizes our findings. To start, more than one quarter ( 28 percent) of the sampled articles offer no explicit causal claims, despite making implicit causal claims. This includes five articles published in policy-oriented journals, and seven in academic journals. A typical implicit claim might be that both international and local dynamics contributed to the outbreak of violence in Rwanda and Yugoslavia, but detail on linkages across dynamics or levels is largely missing. At the international level, scholars make common reference to the end of the Cold War and to patterns and trends within the international community, such as U.S. disengagement, Realpolitik dynamics (Belgian and subsequent French support for the Hutu-dominated government in Rwanda, German support for Croatian and Slovenian

\footnotetext{
${ }^{18}$ This is based on two recently published textbooks on violent conflict and civil wars: Demmers (2016) Mason and Mitchell (2016).
} 
independence), and the weakness of the United Nations system. Local or domestic claims typically highlight the role of state weakness, the rise of nationalism, the military and/or political dominance of one ethnic group (perceptions of historical Tutsi dominance in Rwanda and similar dynamics across groups in Yugoslavia), and grievances among other groups.

Table 2: Results ( $\mathrm{N}=43)$

\begin{tabular}{lrr}
\hline 1. Causation implicit or absent & $12(28 \%)$ \\
2. Causation explicit & \multicolumn{2}{c}{$31(72 \%)$} \\
2.1 Causal Narratives (N=31) & 11 \\
Attitudes & 12 \\
Conditions & 8 \\
Both & \\
& \\
2.2 Ethnicity as a cause $(\mathrm{N}=31)$ & 18 \\
Yes & 13 \\
No & \\
& \\
2.3 Causal Understandings $(\mathrm{N}=31)$ & 28 \\
Empirical Generalization & 0 \\
Dispositional & 2 \\
Configurational & 1 \\
Dialectical & \\
& \\
2.4 Mechanisms (N=31) & 4 \\
Explicit & 5 \\
Implicit & 22 \\
Not invoked &
\end{tabular}

Total

43

Thirty one articles contain explicit causal narratives, and are almost evenly divided between the "attitudes" and "conditions" perspectives. "Attitudes" articles consistently stress the role of agency, most often in terms of elite manipulation, from a rationalist or constructivist angle. Articles that offer conditions-centered narratives regularly underscore the role of structures-external factors such as colonial history or "systems of ethnic stratification." As an example of an "attitudes"-based argument, Caspersen argues that ethnic 
conflict is a function of the rational pursuit of influence by ruling elites at the expense of their rivals (2008, 241-2). Popular grievances become ethnic when leaders find it in their interest to exploit these grievances by "playing the ethnic card". As such, mobilization based on ethnic attitudes results in violence when radical leaders outbid moderates, or when moderates turn radical. Adopting a perspective that prioritizes "conditions," Costalli and Moro contend that the severity of violence relates to three conditions tied to the ethnic distribution of the population: the state of ethnic polarization, fractionalization, and heterogeneity (2012). A minority of articles (eight) propose a mixed narrative, attributing a predominant role to either attitudes or conditions, but acknowledging the contributing role of the other. None of the articles, however, propose what could be categorized as a true hybrid approach that fully blends both perspectives. Finally, among articles advancing explicit causal claims, we found that eighteen posit some direct or indirect link between ethnic identity and conflict, while thirteen reject or minimize the existence of such a link.

The specific causal language deployed in these articles merits its own study (see supplementary file online, Appendix 3). The ten most frequently employed words are "cause" (used as a noun and verb), "likely", "lead" (metaphorical, as in "lead to"), "variable" (referring to characteristic or quantity, not to "unknowns" as in logic and mathematics), “create" (metaphorical), "factor" (used interchangeably with "variable"), "result" (used both as a noun and verb), and "role" (metaphorical, as in "plays a role"). These and other causal words tend to be undefined. More importantly, no study mentions "causation" or "causality."

With regards to causal understandings, our results point to the absolute predominance of empirical generalization. Twenty eight explicitly causal studies belong in this category, suggesting that the subfield is a philosophical monoculture regarding causation. Of these, half (fourteen) adopted a "probability association" perspective best suited for large-N correlational research. The other half focused on conditions. We coded nine articles as articulating a 
"conditioning" understanding of causation, and five as hybrids between "conditioning" and "necessity/sufficiency." An example of the latter is Kaufman's use of the concepts of initial and necessary conditions. In his schema, ethnic fears and myths precede ethnic mobilization, which then interact with security dilemmas to lead to violent conflict $(2006,52-3,58)$.

Only three articles propose an alternative understanding of causation. Two were coded as "configurational" after considerable inter-coder debate. ${ }^{19}$ One is Sherrill Stroschein's study of ethnic violence and partition in Bosnia and Herzegovina, which she analyses in terms of causal mechanisms that begin and end with the actions of manipulative, self-perpetuating elites $(2006,54)$. The other is Lee Ann Fujii's work of popular participation in the Rwandan genocide, in which she explains violence through an analysis of social ties and the ways in which they became salient in specific contexts $(2008,568)$. While both authors emphasize the significance of social structures in conflict, some of which are ethnicized, their focus is on the complex relationship between the processes of mobilization, participation, and organization on the one hand, and violence on the other-a relationship that is itself productive of ethnicity. Neither author commits herself to a post-Humean conception of causation explicitly, although their research designs or sensibilities reveal a tacit preference for adequate causal explanations.

Zalewski's (1995) discussion of feminist perspectives on Bosnia is the third outlier. We coded this article as "dialectical" because of the author's critical stance towards categories typically used in analyses of ethnic war. If we accept that scholarly language invents reality rather than reflects it, Zalewski contends that all scholarly concepts, including causation, are contingent in terms of their meanings and hence contestable. Of all the articles in the sample, Zalewski's also constitutes the most direct attack on treating ethnicity as either

\footnotetext{
${ }^{19}$ Achieving inter-coder agreement on causal understandings proved easier than on causal narratives (see supplementary file online, Appendix 2).
} 
a unit of analysis, as most large-N research does, or as an outcome of war. Both practices prevent scholars from examining a number of pressing questions in the study of ethnic conflict.

The last findings concern the recourse to counterfactual reasoning and causal mechanisms. Counterfactuals were deployed in only three articles that all fall under the empirical generalization rubric, as opposed to the configurational category. Although counterfactuals are a critical tool for most types of causal inference and most causal claims can be reformulated in counterfactual terms, researchers used them very infrequently and relatively superficially. ${ }^{20}$ The language of causal mechanisms appeared in four articles explicitly and five implicitly, but in no case was the concept articulated clearly. And, in neither case, when authors referred to counterfactuals or when they discussed mechanisms, was the reader granted an opportunity to reflect on the philosophies of causation underlying the causal explanation on offer.

\section{Towards Greater Reflexivity}

We take away two points from these results. First, there seems to be a lack of reflexivity in the subfield. Second, the causal ground we stand on is, for the most part, excessively narrow. A good portion of the articles surveyed deal with causation by debating specific factors behind the occurrence of violence-what we call the level of causal narratives. However, once we move beyond these debates to the concept of causation itself, and to the level of causal understandings, the results give us reason for concern.

\section{What is at Stake?}

\footnotetext{
${ }^{20}$ An exception is the 2015 issue of Security Studies on counterfactuals.
} 
Since causal language is very rarely, if ever, defined, it would seem that definitions and meanings of causation are obvious or taken for granted. Yet nothing suggests that it is safe to assume that the community of scholars studying ethnic conflict shares definitions and meanings of causation, though the practice of not providing definitions for the causal concepts they deploy suggests scholars may think so.

The fact that positivist probabilistic language has become the lingua franca in the subfield compounds the problem. But more than a simple question of linguistic preference, this highlights instead the important disjunction that exists between scholarly aims and researchers' causal grounds. Indeed, many philosophers would consider a probabilistic view, let alone language, wholly inappropriate for examining social complexities via qualitative case studies.

Unsurprisingly, the dominance of probabilistic language, even in articles claiming to be alternatives to the positivist mainstream, reflects a deeper form of dominance at the level of causal understandings: the absolute predominance of empirical generalization, largely under the guise of probabilistic understandings and some conditioning contributions. Some take conditioning as a valid alternative to empirical generalization. Viewed from a broader philosophical perspective, however, "probabilistic" and "conditions" understandings both rest on core assumptions of Humean causation. What is taken as vibrancy, or in Varshney's words "substantial progress" $(2009,275)$, in terms of debates regarding ethnic conflicts boils down to variation on the same theme at the level of causal understandings.

We are not the first to decry the lack of philosophical reflexivity and pluralism in scholarship on collective violence. As the subfield began expanding in the 1990s, Suganami $(1996,10)$ expressed similar concerns. And the trend endures twenty years later. ${ }^{21}$ While the literature on ethnic conflict has grown in size and sophistication in recent decades, nothing

\footnotetext{
${ }^{21}$ See, for example, Greiff and Greiff (2016, 271). More generally, see Godfrey-Smith (2009).
} 
suggests that the claims and conceptualizations of causation authors deploy demonstrate more reflexivity or have become significantly richer in the late 2000s and early 2010s. Indeed, the trend may very well be a self-fulfilling one, the most pernicious side effect of our lack of reflexivity. Positivist approaches dominate today's social sciences (Jackson 2011, 40; Shapiro 2005), which impacts our understandings of causation. Scholars operate with a menu of seemingly easy commonplaces, and are little aware of their choices in terms of alternatives and their reinforcing impacts. To paraphrase Lebow's gorilla analogy again, being unreflexive has fed our 900-pound gorilla. Because we pay little attention to how we as scholars and as a community(ies) deploy causation, we may have unwittingly contributed to keeping ourselves on narrow causal ground.

It is high time for reflexivity with regards to causation and how it is deployed in scholarship on ethnic conflict. With a growing number of scholars now turning to more eclectic causal narratives (e.g. Justino et al. 2013; Lyall 2015), possibly signaling a new era post attitudes-conditions debate, we need causal accounts to more clearly engage with causation. This might include discussions of specific language that is better suited for specific narratives, more clarity on meanings and definitions, etc. Moreover, causal narratives should connect reflexively with deeper assumptions regarding causation, i.e. causal understandings.

\section{Values Added, Values Subtracted}

To better understand the potential contributions of increased reflexivity and greater causal pluralism, we turn to a selection of articles representing different types of causal understandings. We believe each type of causal understanding offers its own value added to the subfield - and value subtracted, especially if deployed in isolation.

We begin with the sole dialectical article in our sample. Zalewski's piece (1995) is a classic post-positivist attempt to "complicate" the interpretation of the Yugoslav wars that 
otherwise dominated many Western scholarly and media outlets in the 1990s. The author's main goal is to sensitize the reader to the underlying intellectual and political structures that condition knowledge production regarding these conflicts, including the normative choices that guide our research questions and research designs. In so doing, she problematizes the fixity of key concepts that scholars use to analyze the carnage in Yugoslavia and simultaneously opens theoretical and analytical space for alternative sociological forms. She makes room for gender in particular, but also opens space for entire new fields such as Critical Security Studies (CSS). ${ }^{22}$

From our perspective, the challenge for this type of project is to develop a methodology that broadens the domain of inquiry into "ethnic" conflicts without ignoring or precluding causal thinking altogether. We can agree with Zalewski and other scholars who advance similar stances that mainstream perspectives on civil wars systematically elide other dimensions, including the gendered dimension of such wars. But the point here is that our judgment, much like Zalewski's, is based on some form of causal analysis: the observation of the dominant epistemic community and its knowledge production practices, and the attendant claim that these practices are embedded in broader dynamics of gendered power.

In Fujii’s (2008) article, we see instead a configurational understanding of causation. Building on her field-intensive, ethnographic work, Fujii examines the kinds of evidence that alternative theories ignore, namely how ties and networks factored in people's motivation to kill during the genocide. Indeed, one of her starting points is to move beyond ethnicity and

\footnotetext{
${ }^{22}$ Consider three recently published CSS methodology textbooks. All three argue against the Humean model of causation. One calls for non-causal thick descriptions in the Geertzian tradition (Jarvis 2013, 242), one for following neither Hume nor Geertz but William Connolly (Salter 2012, 3), and one for radical methodological creativity regarding our research ideas and practices, including causal claims (Aradau et al. 2014, 3). Van Ingen (2016: 393-4) calls this literature "ideographic" (i.e.: non-nomological).
} 
"aggregation at the level of the ethnic group," which lead scholars to neglect other "situational and social dynamics" $(2008,571)$. This allows her to traverse different levels or scales of conflict analysis, and to provide a richer account of the genocide—what she dubs a “processual” causal account $(2008,572)$ of different paths to participation. Fujii does not deny the link between identity politics and genocide, but goes a step further to show the much grittier, or "granular" in her words $(2006,187)$, reality of participation in violence. This reality blurs the otherwise assumed distinctions between individual and social levels of analysis, for example.

Her stance suggests a predilection for an adequate understanding of causal relations over a generalizable one. Hers is an implicit call to eschew the desire to generalize, as many like her, who have opted for a turn to micro-dynamics of conflict, are doing. In so doing, she paints very rich renderings of local mobilization and participation dynamics, including their idiosyncratic side. In striving for this causal adequacy, however, the greatest challenge configurational scholars face is developing the ability to speak in one voice in order to propose an alternative to existing stances, especially in terms of mounting a coherent challenge at the level of causal narratives, where most debates are taking place.

Configurational perspectives like Fujii's are also valuable because of their ability to incorporate causal relations surrounding discourse-a concept that most empirical generalizers either bracket (as epiphenomenal) or ignore, and one that most postpositivists treat as non-causal or a-causal. Configurationalists themselves approach discourse in different ways. One approach begins with the notion that discourses (or more specifically "discursive reproduction") constitute shared collective beliefs that render society real. Invoking Weber's notion of adequate causation, Vujačić (2015) analyzes for example the dissolution of Yugoslavia in the context of the prevailing discourse on the role of the state within Serbia, as the country's "core nation." From this perspective, had the state and nation been historically 
constituted as separate in Serbia as they had been in Russia, the Yugoslav federation would have survived much like the Russian one.

Another approach is to treat discourses as a causal mechanism on par with elements such as greed or networked mobilization. Discourse analysis of rhetoric promoted by politicians, intellectuals, publics, and especially, the media before, during, and after Yugoslav conflicts researchers identify the so-called conditions of possibility or enabling/constraining contexts that relate to mass violence (Žarkov 2007; Kolstø 2016). Indeed, just because discourse analytic research on collective violence rarely uses the tropes and metaphors that many readers of the journals we surveyed recognize as causal, it does not mean that its insights could not add to causal explanations of the outcomes under study (Kurki and Suganami 2012, 413).

This brings us to the dispositional perspective-an ideal-type absent from our sample. This is by far the least explored type of causal understanding in conflict studies, as illustrated recently by Van Ingen (2016). Building on Bhaskarian critical realism in philosophy and its reappropriation in IR, he posits a mechanism-based understanding of causation as a muchneeded alternative to both empirical generalization and what he calls "ideographic research" or post-positivist alternatives to empirical generalization. Van Ingen's starting point is ontological: critical realists think of mechanisms as real, whether or not they are experienced or observed as in the Humean model of causation. Mechanisms produce events-in this context they are variously called actual, empirical, and/or particular-in conjunction with other mechanisms. And while mechanisms operate in open systems and produce unique events, they are nevertheless generalizable qua mechanisms (Van Ingen 2016, 403-4). Viewed as such, the violence in Rwanda and Yugoslavia are unique phenomena with unique causal pathways involving multiple and occasionally mutually exclusive mechanisms. We can, however, identify complex combinations of capacities behind the violence. 
Thinking through this perspective is important in light of the increasing attention critical realism is garnering in the social sciences (Archer 1998)—despite not necessarily translating into its actual use-and considering the wave of interest in causal mechanisms and mechanism-based arguments in the subfield (Varshney 2009). Judging by our sample, the language of causal mechanisms is used mostly pragmatically: authors use it to signal the inter-connectedness of multiple entities that they argue caused an outcome. This is however rarely, if ever, accompanied by an explanation of what causal mechanisms are and how they operate. The problem is compounded by the often-interchangeable use of concepts such as "mechanism" and "process," despite stricter philosophical definitions that see them as different things, or as a component of the other. ${ }^{23}$ We have yet to see what form the value substracted of a dispositional perspective takes for the subfield.

Finally, we turn to empirical generalization. Consider Gagnon's (1994-5) explanation of the Yugoslav war. Contra the ethnic or ancient hatreds thesis popular in the Western media in the 1990s, he stresses "the dynamics of within-group conflict," namely the idea that authoritarian ruling elites (“conservatives") promoted violence as a means of demobilizing opposition ("reformists") to perpetuate their positions of power (while also plundering stateowned resources). Gagnon's argument is compelling, as is his refusal to treat ethnicity as a given (Gagnon 1994-5, 131, fn.4). However, the author's desire to test hypotheses and generalize to cases beyond Yugoslavia, namely Russia, is also a limitation. A different school of causal analysis would have allowed him to go beyond five episodes of elite manipulation and account for a broader confluence of causal processes that enabled power-holdersespecially in Serbia but also in other republics (Gagnon 1994-5, 134, fn. 17) — to successfully espouse violent nationalism in the 1990s. For example, each episode that Gagnon examines

\footnotetext{
${ }^{23}$ Compare Cartwright (2014, 319); Kutach (2014, 42); Risjord (2014, 226); Vaidyanathan et al. (2015, 8). Also see Gorski (2009), Gerring (2010) and Lebow (2014, Ch. 3).
} 
could be regarded as a unique configuration of evolving, if path-dependent myths, symbols, and rhetoric regarding state-nation relations that later influenced nationalist mobilization and participation dynamics (Vujačić 2015, 15-49).

Consider also Kaufman's (2006) attempt to engage different scholarly camps. In addition to bridging the attitudes-conditions divide in his causal narratives, ${ }^{24}$ Kaufman also pushes boundaries in terms of causal understandings. Indeed, unsatisfied with naïve generalizations, he explores ways of supplementing probabilistic claims with conceptualizations based on necessity/sufficiency and conditioning, thus adding layers of complexity. This helps explain the attractiveness of the models he has proposed over the years. In particular, their blended approach achieves greater explanatory reach than segregated causal narratives across the attitudes-conditions divide, and stands on recognizable causal ground for the majority of ethnic conflict researchers. Yet, for all of its sophistication and openness on causation, Kaufman's scholarship also faces limitations. ${ }^{25}$ For example, he never incorporates the notion that language constructs reality. This has implications for his understanding of ethnicity, or ethnic identity, which he holds as the variable of import in the analysis of ethnic conflicts in the form of "definitions of identity" or "myth-symbol complexes" that groups eventually come to develop (Kaufman 2006, 50).

A more reflexive stance would be to ask whether ethnicity, as a concept, is necessarily appropriate or useful in explaining the outcomes under study, or to at least (also) treat it as an explanandum rather than an explanans. After all, many Rwandanists have argued that privileging ethnicity over and above other social relations, or even treating it as analytically separate, has "corroded" even basic interpretations of Rwandan history, to say nothing of the accounts of the 1994 genocide (Newbury and Newbury 2000, 832; Desrosiers 2014). A

\footnotetext{
${ }^{24} \mathrm{We}$ refer here to his articulation of the relationship between social and psychological factors behind mobilization (discourse construction and what discourse plays upon, such as fears), and his reference to the contextual elements that opportunities scholars prioritize, such as the space for violence within a specific state.

${ }^{25}$ It should be noted that in his latest work Kaufman (2015) approaches "ethnicity" via more reflexive means.
} 
commonly made point is that ethnicity is a social kind, not a natural kind, and that scholarsperhaps especially Western ones (Spivak 1999, 60, 110)—should seek to explain the specific causal pathways that "ethnicize" social reality (Bowman 2001). At a minimum, this calls for investigating ideologies, discourses, and practices of daily life. In the case of Rwanda, this includes evaluating how Rwandans, especially non-elites, have always navigated a universe much more liminal than our ethnicizing renderings suggest (Desrosiers 2018b). The perspective is likely to help researchers uncover alternate meanings about the nature and changing dynamics of status hierarchies, forms of oppression and how they intersect with each other, illuminating the conditions under which shared understandings relating to ethnic war and genocide, including the shared understandings of their causes, are (re)produced, challenged, and transformed from the ground up.

In the case of Yugoslavia, critically-minded "local" scholars, together with their allies in area studies or adopting various deconstructive methodologies, insist on the need to decenter ethnicity from explanations of violence in the 1990s. Some have drawn attention to the idea that ethnic identities and identifications cannot be conceptualized as fixed and unified, but rather as heterogeneous, contested, loosely integrated, and formed interactively with a host of social and cultural formations, such as class, media, or educational systems (Bougarel, Helms and Duijzings 2007; Vujačić 2015; Hromadžić 2015; Archer, Duda and Stubbs 2016). Others have argued that the issue for our analyses is not what ethnicity is, but what it does as a relation of power-that is, how groups become ethnicized (and also gendered and sexualized, as per Žarkov 2007 and Helms 2013; see also Campbell 1998).

A good example of a more causally reflexive and pluralistic analysis of the Rwandan and Bosnian conflicts comes from Malešević (2006). Building on previous research in sociology, Malešević calls attention to links between genocide and modernity at the macro level, and to links between social status transformation and ethnic mobilization at the micro 
level. In addition to "the ideology and technology of modernity", it was a confluence of "status vacuums" caused by state collapse, democratization and the shifting geopolitical environment that created the conditions under which mass extermination became a plausible course of action (Malešević 2006, 226). Given that said status vacuums may be vested in decidedly non-ethnic relations, the challenge for scholars is to examine the variability and contingency of putative ethnic conflicts.

Indicatively, many scholars from, and of, Rwanda and the Yugoslav region tend to be drawn to such reflexive, pluralistic and, one could add, grounded forms of causal theorizing. From our perspective, this is desirable because it forces researchers to treat ethnicity as a process. It is always in flux and sometimes instantiated through acts of violence. It also forces researchers to resist, in contemporary ethnographic fashion, advancing their "own" ethnic claims, whatever these might be.

In sum, our purpose is not to offer a new theory of ethnic conflict centered on a specific causal narrative, or to advocate in favor of a specific causal understanding. Such a move would foreclose efforts at reflexivity and the promotion of pluralism. Instead, fostering reflexivity and pluralism in the study of ethnic conflict should be a shared responsibility. Proponents of the dominant Humean view do not often do so, but need to engage reflexively with causation. However, the onus is not solely on them. All too often, their critics deliberately focus on non-causal or a-causal claims, or reject any engagement with causal concepts or notions of causation. Given the variety and breadth of causal understandings in philosophy, this ritual of abjuring causal claims in broad, sweeping terms is out of place. We urge scholars to open themselves to a wider set of causal understandings, so as to foster dialogue based on different causal inferences (Vucetic 2011, 1307-1311; Grynaviski 2012). This will provide the scholarly community with a better sense of causation with regards to ethnic conflicts, and a deeper understanding of how our work shapes knowledge production in 
our subfield. In fact, even if we assume that theoretical contradictions and

incommensurabilities will always remain, leaving us with partial and provisional accounts of civil wars, at best (van Ingen 2016, 410-1), the implications in terms of understanding where both our causal language and assumptions stem from, how they are received by others, and in the end made to matter for the subfield, are well worth it.

\section{Conclusion}

Following reflexive approaches to causation introduced recently in sociology, political science, IR and other fields, this paper has examined the main causal narratives and causal understandings in scholarship on the conflicts in Rwanda and Yugoslavia in the early 1990s. The results of our analysis confirmed the lack of reflexivity over causation in ethnic conflict studies. Just as importantly, causal thinking in this literature is too narrow. To be sure, the articles surveyed explain these conflicts in terms of either attitudes, conditions, or both, and also demonstrate diversity with regards to the role that identity plays in conflicts at the level and scale of causal narratives. What is missing, however, is a discussion of how these narratives employ causal language or relate to prior, but implicit, causal understandings.

Indeed, once we move beyond the debates that have consumed the subfield in recent decades to the notions and meanings of causation themselves, the results give us reason for concern. Most studies appear to privilege empirical generalization, a model that is problematic for qualitative case studies, especially in its probabilistic form.

We recommend that scholars working on ethnic conflict engage more philosophically with causal thinking. Indeed, it is our conviction that both empirical generalizers and their critics could benefit from engaging reflexively with their assumptions about causes and effects, counterfactuals, causal mechanisms, or, for that matter, the illusory nature of all of these concepts. Greater awareness of the diversity of philosophical positions on causation has 
a real potential to inspire more self-aware, pluralistic research practices in the subfield, thus recasting and even reinvigorating the production of scholarly knowledge related to the nature of collective violence, ethnic and otherwise.

This then has the potential to inform policy discourse in a number of ways. Arguably, the most consequential policy change would be an abandonment of the heretofore dominant ethnic lens, and a greater appreciation of the ways in which conflict is connected to, and entangled with, gender, race, class, sexuality, post-coloniality, and other forms of power. But we also call on the community of conflict scholars to recognize that the policy recommendations that we promote always depend on the positionality of authors and their communities, and how their underlying causal narratives and causal understandings shape their understanding of the problem of ethnic conflict. Our position is that most types of scholarship, from simple empiricism to a-causal poststructuralism, can generate valuable knowledge on which to build policy-relevant insights. However, we should worry when policy responds to intellectual monocultures. Evidence-based policy should acknowledge the contestable and contested nature of evidence, and of our basic notions of causation and claims about "what made this happen." We as scholars should bring policymakers into these reflexive conversations, not shield them from the debate for the sake of expediency and providing straightforward "advice to the prince." 


\section{References}

Abend, Gabriel, Caitlin Petre, and Michael Sauder. 2013. "Styles of Causal Thought: An Empirical Investigation.” American Journal of Sociology 119 (3): 602-54.

Aradau, Claudia, Jef Huysmans, Andrew Neal, and Nadine Voelkner. 2014. "Introducing Critical Security Methods.” In Critical Security Methods: New Frameworks for Analysis, edited by Claudia Aradau, Jef Huysmans, Andrew Neal and Nadine Voelkner, 1-22. London: Routledge.

Archer, Margaret. 1998. "Introduction: Realism in the Social Sciences." In Critical Realism: Essential Readings, edited by Margaret Archer, Roy Bhaskar, Andrew Collier, Tony Lawson and Alan Norrie, 189-205. London: Routledge.

Archer, Rory, Igor Duda, and Paul Stubbs. 2016. "Bringing Class Back In: An Introduction". In Social Inequalities and Discontent in Yugoslav Socialism, edited by Rory Archer, Igor Duda and Paul Stubbs, 1-20. London: Routledge.

Angstrom, Jan. 2000. "The Sociology of Studies of Ethnic Conflict: Explaining the Causal Status of Development." Civil Wars 3 (3): 23-44.

Arfi, Badredine. 1998. "Ethnic Fear and the Social Construction of Insecurity.” Security Studies 8 (1): 151-203.

Bougarel, Xavier, Elissa Helms, and Ger Duijzings, eds. 2007. The New Bosnian Mosaic: Identities, Memories, and Moral Claims in a Post-War Society. Farnham: Ashgate.

Bowman, Glenn. 2001. "The Violence in Identity.” In Anthropology of Violence and Conflict, edited by Bettina E. Schmidt and Ingo W. Schröder, 25-46. London: Routledge.

Beebee, Helen, Christopher Hitchcock, and Peter Menzies, eds. 2009. The Oxford Handbook of Causation. Oxford: Oxford University Press.

Campbell, David. 1998. National Deconstruction: Violence, Identity, and Justice in Bosnia. Minneapolis: University of Minnesota Press. 
Cartwright, Nancy. 2014. “Causal inference.” In Philosophy of Social Science: A New Introduction, edited by Nancy Cartwright and Eleonora Montuschi, 308-26. Oxford: Oxford University Press.

Caspersen, Nina. 2008. "Intragroup Divisions in Ethnic Conflicts: From Popular Grievances to Power Struggles.” Nationalism and Ethnic Politics 14 (2): 239-65.

Cederman, Lars-Erik. 2013. "Nationalism and Ethnicity.” In Handbook of International Relations, $2^{\text {nd }}$ edition, edited by Walter Carlsnaes, Thomas Risse and Beth Simmons, 531-54. London: Sage.

Collier, Paul, and Anke Hoeffler. 2004. "Greed and Grievance in Civil War.” Oxford Economic Papers 56 (4): 563-95.

Costalli, Stefano, and Francesco N. Moro. 2012. "Ethnicity and Strategy in the Bosnian Civil War: Explanations for the Severity of Violence in Bosnian Municipalities.” Journal of Peace Research 49 (6): 801-15.

Demmers, Jolle. 2016. Theories of Violent Conflict: An Introduction. $2^{\text {nd }}$ Edition. London: Routledge.

Desrosiers, Marie-Eve. 2014. "Rethinking Political Rhetoric and Authority During Rwanda's First and Second Republics." Africa 84 (2): 199-225.

Desrosiers, Marie-Eve. 2018a. "A Sociological Look at the Evolution of Recent Scholarship on Ethnic Conflicts." Journal of International Relations and Development 21 (3): 580-607.

Desrosiers, Marie-Eve. 2018b. "Rwandans under the First and Second Republics: Understanding the Realm of the Abaturage and "Making Do" with Authoritarianism", unpublished manuscript.

Fearon, James D. 1995. “Rationalist Explanations for War.” International Organization 49 (3): $379-414$. 
Fearon, James D., and David D. Laitin. 2000. "Violence and the Social Construction of Ethnic Identity.” International Organization 54 (4): 845-77.

Fearon, James D., and David D. Laitin. 2003. "Ethnicity, Insurgency, and Civil War." American Political Science Review 97 (1): 75-90.

Feldman, Martha S., Kaj Sköldberg, Ruth Nicole Brown, and Debra Horner. 2004. "Making Sense of Stories: A Rhetorical Approach to Narrative Analysis.” Journal of Public Administration Research and Theory 14 (2): 147-70.

Finlay, Linda. 2002. "Negotiating the Swamp: The Opportunity and Challenge of Reflexivity in Research Practice." Qualitative Research 2 (2): 209-30.

Flyvbjerg, Bent. 2006. “Five Misunderstandings about Case-Study Research.” Qualitative Inquiry 12 (2): 219-45.

Fujii, Lee Ann. 2006. Killing Neighbors: Webs of Violence in Rwanda. Ithaca, NY: Cornell University Press.

Fujii, Lee Ann. 2008. “The Power of Local Ties: Popular Participation in the Rwandan Genocide." Security Studies 17 (3): 568-97.

Gerring, John. 2010. “Causal Mechanisms: Yes, But....” Comparative Political Studies 43 (11): $1499-1526$.

Godfrey-Smith, Peter. 2009. "Causal pluralism.” In The Oxford Handbook of Causation, edited by Helen Beebee, Christopher Hitchcock and Peter Menzies, 326-337. Oxford: Oxford University Press.

Goertz, Gary, and Jack S. Levy. 2007. Explaining War and Peace: Case Studies and Necessary Conditions Counterfactuals. London: Routledge.

Gorski, Philip. 2009. "Social 'Mechanisms' and Comparative-Historical Sociology: A Critical Realist Proposal.” In The Frontiers of Sociology, edited by Björn Wittrock and Peter Hedström, 147-94. Leiden: Brill. 
Greiff, Tobias, and Jacquie L. Greiff. 2016. "This Causes Conflict! - On the Risks of Establishing Causalities through Conflict Analysis and the Consequences of Implementing those Logics in Conflict Resolution Strategies.” In Questioning Causality: Scientific Explorations of Causes and Consequences across Social Contexts, edited by Rom Harre and Fathali Moghaddam, 259-275. Santa Barbara: Praeger.

Grynaviski, Eric. 2013. “Contrasts, Counterfactuals, and Causes.” European Journal of International Relations 19 (4): 823-46.

Guzzini, Stefano. 2017. "Power and Cause.” Journal of International Relations and Development 20 (4): 737-759.

Elissa Helms. 2013. Innocence and Victimhood: Gender, Nation, and Women's Activism in Postwar Bosnia-Herzegovina. Madison, WI: University of Wisconsin Press.

Hoffman, Daniel. 2011. "Violence, Just in Time: War and Work in Contemporary West Africa." Cultural Anthropology 26 (1): 34-57.

Horowitz, Donald L. 1985. Ethnic Groups in Conflict. Berkeley: University of California Press.

Horowitz, Donald L. 2002. "Explaining the Northern Ireland Agreement: The Sources of an Unlikely Constitutional Consensus.” British Journal of Political Science 32 (2): 193 220.

Hromadžić, Azra. 2015. Citizens of an Empty Nation: Youth and State-Making in Postwar Bosnia-Herzegovina. Philadelphia: University of Pennsylvania Press.

Humphreys, Adam R. C. 2018. "Realism, Empiricism and Causal Inquiry in International Relations: What is at Stake?.” European Journal of International Relations, advanced online publication. 
Jackson, Patrick T. 2011. The Conduct of Inquiry in International Relations: Philosophy of Science and its Implications for the Study of World Politics. London: Routledge.

Jarvis, Lee. 2013. “Conclusion: The Process, Practice and Ethics of Research.” In Critical Approaches to Security: An Introduction to Theory and Methods, edited by Laura J. Shepherd, 236-47. London: Routledge.

Justino, Patricia, Tilman Brück, and Peter Verwimp. 2013. "Micro-Level Dynamics of Conflict, Violence, and Development: A New Analytical Framework.” In Micro-level Perspective on the Dynamics of Conflict, Violence and Development, edited by Patricia Justino, Tilman Brück and Philip Verwimp, 3-29. Oxford: Oxford University Press.

Kaufman, Stuart J. 2001. Modern Hatreds: The Symbolic Politics of Ethnic War. Ithaca, NY: Cornell University Press.

Kaufman, Stuart J. 2006. "Symbolic Politics or Rational Choice? Testing Theories of Extreme Ethnic Violence.” International Security 30 (4): 45-86.

Kaufman, Stuart J. 2015. Nationalist Passions. Ithaca, NY: Cornell University Press.

Keen, David. 2012. “Greed and Grievance in Civil War.” International Affairs 88 (4): 757-77.

Kolstø, Pål. 2009. "Discourse and Violent Conflict," In Media Discourse and the Yugoslav Conflicts: Representations of Self and Other, edited by Kolstø, 1-20. Farnham, Ashgate.

Kurki, Milja, and Hidemi Suganami. 2012. "Towards the Politics of Causal Explanation: A Reply to the Critics of Causal Inquiries." International Theory 4 (3): 400-29.

Kutach, Douglas. 2014. Causation. Cambridge: Polity.

Lange, Matthew. 2013. Comparative Historical Methods. London: Sage. 
Lyall, Jason. 2015. "Process Tracing, Causal Inference, and Civil War.” In Process Tracing: From Metaphor to Analytic Tool, edited by Andrew Bennett and Jeffrey T. Checkel, 186-207. Cambridge: Cambridge University Press.

Lebow, Richard Ned. 2014. Constructing Cause in International Relations. Cambridge: Cambridge University Press.

Mackie, J. L. 1965. “Causes and Conditions.” American Philosophical Quarterly 2 (4): 24564.

Mahoney, James. 2008. “Toward a Unified Theory of Causality.” Comparative Political Studies 41 (4/5): 412-36.

Mahoney, James, Erin Kimball, and Kendra L. Koivu. 2009. “The Logic of Historical Explanation in the Social Sciences." Comparative Political Studies 42 (1): 114-46.

Mahoney, James, and Dietrich Rueschemeyer. 2003. Comparative Historical Analysis in the Social Sciences. Cambridge: Cambridge University Press.

Malešević, Siniša. 2006. Identity as Ideology: Understanding Ethnicity and Nationalism. New York: Palgrave Macmillan.

Mason, David T. and Sara McLaughlin Mitchell. 2016. What do We Know about Civil Wars?. Lanham: Rowman \& Littlefield.

McMillan, Kevin. 2018. The Constitution of Social Practices. New York: Routledge. Newbury, David and Catharine Newbury. 2000. "Bringing the Peasants Back In: Agrarian Themes in the Construction and Corrosion of Statist Historiography in Rwanda." The American Historical Review 105 (3): 832-877.

Phillips, Brian J. 2014. "Ranking IR Journals”, Duck of Minerva, January 7. http://www.duckofminerva.com/2014/01/ranking-ir-journals.html (July 6, 2015).

Risjord, Mark. 2014. Philosophy of Social Science: A Contemporary Introduction. London: Routledge. 
Ross, Marc Howard. 1997. “The Relevance of Culture for the Study of Political Psychology and Ethnic Conflict.” Political Psychology 18 (2): 299-326.

Ross, Marc Howard. 2007. Cultural Contestation in Ethnic Conflict. Cambridge: Cambridge University Press.

Salter, Mark. 2012. “Introduction.” In Research Methods in Critical Security Studies: An Introduction, edited by Mark Salter and Can E. Mutlu, 1-14. London: Routledge.

Schatz, Ed, ed. 2015. “Symposium: Linking Interpretation and Causal Inference.” Qualitative \& Multi-Method Research 13 (2): 3-27.

Shapiro, Ian. 2005. The Flight from Reality in the Human Sciences. Princeton, NJ: Princeton University Press.

Sil, Rudra, and Peter Katzenstein. 2010. Beyond Paradigms: Analytic Eclecticism in the Study of World Politics. New York: Palgrave MacMillan.

Spivak, Gayatri Chakravorty. 1999. A Critique of Postcolonial Reason. Harvard: Harvard University Press.

Steinberg, David A., and Stephen M. Saideman. 2008. "Laissez Fear: Assessing the Impact of Government Involvement in the Economy of Ethnic Violence.” International Studies Quarterly 52 (2): 235-59.

Stroschein, Sherill. 2005. "Examining Ethnic Violence and Partition in Bosnia-Herzegovina." Ethnopolitics 4 (1): 49-64.

Suganami, Hidemi. 1996. On the Causes of War. Oxford: Clarendon Press.

Vaidyanathan, Brandon, Michael Strand, Austin Choi-Fitzpatrick, Thomas Buschman, Meghan Davis, and Amanda Varela. 2015. "Causality in Contemporary American Sociology: An Empirical Assessment and Critique.” Journal for the Theory of Social Behavior 46 (1): 3-26. 
Van Ingen, Michiel. 2016. "Conflict Studies and Causality: Critical Realism and the Nomothetic/Idiographic Divide in the Study of Civil War." Civil Wars 18 (4): 387416.

Varshney, Ashutosh. 2009. "Ethnicity and Ethnic Conflict.” In The Oxford Handbook of Comparative Politics, edited by Carles Boix and Susan C. Stokes, 274-294. Oxford: Oxford University Press.

Vigh, Henrik. 2006. Navigating Terrains of War: Youth and Soldiering in Guinea-Bissau. Oxford: Berghahn.

Vucetic, Srdjan. 2011. "Genealogy as a Research Tool in International Relations." Review of International Studies 37 (3), 1295-1312.

Vujačić, Veljko. 2015. Nationalism, Myth, and the State in Russia and Serbia: Antecedents of the Dissolution of the Soviet Union and Yugoslavia. Cambridge: Cambridge University Press.

Ylikoski, Petri. 2012. "Micro, Macro, and Mechanisms.” In The Oxford Handbook of Philosophy of the Social Sciences, edited by Harold Kincaid, 21-45. Oxford: Oxford University Press.

Zalewski, Marysia. 1995. "Well, What is the Feminist Perspective on Bosnia?'." International Affairs 71 (2): 339-56.

Žarkov, Dubravka. 2007. The Body of War: Media, Ethnicity, and Gender in the Break-up of Yugoslavia. Durham, NC: Duke University Press. 